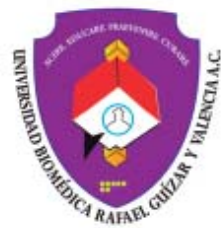

Vol. 8, Núm. 2

Julio-Diciembre 2021. pp. 82-88

doi: $10.35366 / 103086$

Información general actualizada

\title{
Trayectoria de una quimera apocalíptica. La vivencia del uso de cubrebocas en tiempos de COVID-19
}

\author{
Trajectory of an apocalyptic chimera. The experience of the \\ use of mouth covers in times of COVID-19 \\ Francisco Aguilar Rebolledo, ${ }^{*}$ Artemio López García, * \\ Hilario Campos Durán, ${ }^{\ddagger}$ Raúl Román Romero Tapia*
}

\section{RESUMEN}

Introducción: Al inicio de la pandemia de la enfermedad del coronavirus 2019 (COVID-19) algunos países implementaron el uso de cubrebocas de forma generalizada. En México la recomendación de su uso entre la población general no ha sido precisa y a veces confusa en las mismas autoridades sanitarias, aunque las fuentes confiables de información lo recomiendan. Material y métodos: La revisión de la literatura se realizó siguiendo el protocolo de Cochrane para revisiones rápidas. La búsqueda incluyó artículos científicos que describieran o evaluaran la transmisión del COVID-19 o infecciones respiratorias agudas en humanos o en espacios públicos abiertos con el uso de cubrebocas o mascarilla. Se utilizaron los buscadores EMBASE y PubMed y se limitaron las fechas de búsqueda del $1^{\circ}$ de enero de 2019 al 31 de agosto de 2021. Resultados: Se examinaron 10 metaanálisis que revisan 150 estudios. Todos los estudios mostraron que el riesgo de cualquier infección respiratoria, incluidas las de coronavirus, disminuía con el uso de cubrebocas en la población general, al igual que en los trabajadores de la salud. De los 10 metaanálisis algunos compararon el uso de cubrebocas FFP2, N95, NK95 con los cubrebocas quirúrgicos, los no quirúrgicos y los de tela, se incluyeron comentarios acerca del uso de caretas encon-

\section{ABSTRACT}

Introduction: At the beginning of the coronavirus disease 2019 (COVID-19) pandemic, some countries implemented the use of face masks in a generalized way. In Mexico, the recommendation for its use among the general population has not been precise and sometimes confusing in the same health authorities, although reliable sources of information recommend it. Material and methods: The literature review was carried out following the Cochrane protocol for rapid reviews. The search included scientific articles that described or evaluated the transmission of COVID-19 or acute respiratory infections in humans or in open public spaces with the use of a face mask or mask. The EMBASE and PubMed search engines were used and the search dates were limited from January 1, 2019 to August 31, 2021. Results: Of 10 meta-analyzes that review 150 studies. All studies showed that the risk of any respiratory infection, including coronavirus, decreased with the use of face masks in the general population, as well as in healthcare workers. Of the 10 meta-analyzes, some compared the use of FFP2, $N-95$, NK95 masks with surgical masks, non-surgical masks and cloth masks. Comments on the use of masks were included, finding some significant differences in terms of protection that are indicated

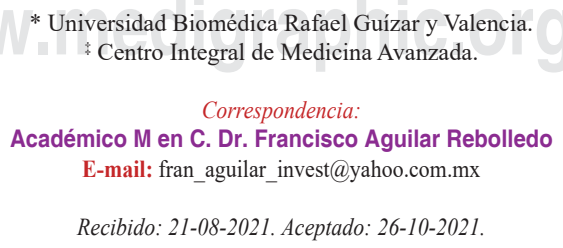

Citar como: Aguilar RF, López GA, Campos DH, Romero TRR. Trayectoria de una quimera apocalíptica. La vivencia del uso de cubrebocas en tiempos de COVID-19. Plast Restaur Neurol. 2021;8 (2): 82-88. https://dx.doi.org/10.35366/103086

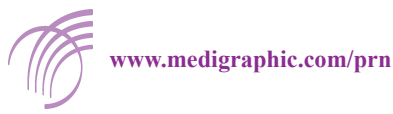


trando algunas diferencias significativas en cuanto a protección que se indican en cada apartado. Conclusión: Existe evidencia científica de que el uso de cualquier cubrebocas disminuye el riesgo de infecciones respiratorias de todo tipo, incluido $\mathrm{CO}$ VID-19. En México, para contener la propagación del virus SARS-CoV-2 y restringir la movilidad de personas, se sugiere implementar el uso del cubrebocas permanente al salir a la calle, la sana distancia y la higiene de manos, ya que estos son los protocolos que han demostrado efectividad científica.

Palabras clave: Cubrebocas, mascarillas, prevención, pandemia, coronavirus, COVID-19.

\section{INTRODUCCIÓN}

Desde comienzos del año 2020, nuestras vidas se han visto condicionadas por una nueva pandemia. La COVID-19, una enfermedad infecciosa causada por un nuevo coronavirus, ha alcanzado todos los rincones del globo, desatando una crisis sanitaria de enormes dimensiones que ha terminado por afectar la vida social, económica y política. Ante este escenario, que algunos dimensionan como apocalíptico, se han desarrollado las más diversas reacciones y reflexiones. Intelectuales, filósofos, comunicadores, académicos y usuarios de las más diversas redes sociales, han tomado la palabra para expresar sentimientos, premoniciones, augurios, quejas, críticas, negaciones y demás: la COVID-19 ha dado para todo. Nunca como ahora, un suceso de carácter mundial ha movilizado tal número de reflexiones. ${ }^{1}$

Con el correr del tiempo, el modo de vincularse con los otros ha cambiado proponiendo formas de comunicación diferente. Por otro lado, y como «salvavidas de cuarentena», han proliferado los memes y diversidad de discursos visuales haciendo referencia a la COVID-19 a partir del humor y la ironía. También han surgido diferentes propuestas para imaginar el después de la pandemia, o en el caso de las artes escénicas y audiovisuales, éstas se están repensando a partir de las nuevas plataformas virtuales.

\section{Breve historia del cubrebocas}

El uso de éstos se remonta a las civilizaciones antiguas. Existe evidencia de su uso en eventos sociales, religiosos, funerarios, conmemorativos, festivos, artísticos y hospitalarios. El registro más antiguo es Plinio el Viejo (79-23 a.C.) que usaba cubrebocas fabricados con la piel de la vejiga de animales. En el siglo XVI Leonardo da Vinci propuso el uso de tela mojada como cubrebocas para prevenir la inhalación de sustancias químicas. No fue hasta finales del siglo XIX cuando el Dr. Berger, in each section. Conclusion: There is scientific evidence that the use of any mask reduces the risk of respiratory infections of all kinds, including COVID-19. In Mexico, to contain the spread of the SARS-CoV-2 virus and restrict the mobility of people, it is suggested to implement other measures of prevalence in addition to the permanent mask when going out, the healthy distance, the hygiene of hands, the protocols that have proven scientific effectiveness (such as the use of permanent masks).

Keywords: Face masks, masks, prevention, pandemic, coronavirus, COVID-19.

en Francia, usó por primera vez un cubrebocas en un quirófano.

Los hitos importantes en la historia del cubrebocas para prevenir infecciones están relacionados a epidemias y pandemias. En el siglo XIV, durante la epidemia de peste negra en Europa, los médicos usaban máscaras en forma de pico que contenían flores, hierbas, especies y algunos líquidos para evitar enfermedades. Según algunos historiadores, la enfermedad entraba a través de los olores. Se creía que el aire contaminado venía del este y que los cubrebocas protegían de los «malos aires» o de «la plaga» por sí misma. La primera vez que se obligó al personal de salud, policías y sepultureros a usar cubrebocas fue en China, en 1910. En la pandemia de influenza de 1918 por primera vez se recomendó el uso del cubrebocas en la población general.

Finalmente, durante la pandemia de influenza de 2009, el uso de cubrebocas se expandió de forma global y se publicaron varios estudios sobre su uso y efectividad. ${ }^{2}$ Los estudios clínicos y científicos formales sobre el uso de cubrebocas comenzaron a finales del siglo XIX y principios del XX.

\section{Formas de transmisión del SARS-CoV-2}

Tiene un diámetro de 0.06 a 0.14 micras. Las partículas virales son casi siempre transmitidas por secreciones respiratorias en forma de gotas de pacientes infectados que tienen dimensiones en el rango de $<0.6$ a 1,000 micras. El virus es llevado directamente por las secreciones respiratorias hacia los sujetos susceptibles, e indirectamente por el contacto con superficies contaminadas por esas secreciones. Estos trabajos sugieren que las gotas gravitan y se asientan a una distancia máxima de aproximadamente dos metros. Con base en estas antiguas investigaciones las políticas de salud pública recomiendan la separación física de dos metros.

Se ha demostrado que cuando una persona tose, estornuda, grita, habla o incluso respira, las secreciones 
respiratorias (cargadas de virus) son emitidas en todos los tamaños. Las gotas mayores a 100 micras caen en menos de tres segundos a una distancia de dos metros, mientras que las que tienen dimensiones de aproximadamente una micra pueden deshidratarse y permanecer como núcleos de gotas en el aire hasta por 12 horas y pueden viajar mayores distancias con las corrientes de aire.

Por sus dimensiones es posible que los aerosoles que contienen al virus sean transferidos hasta regiones más profundas de las vías aéreas. Todo esto apunta a una probable transmisión por gotas generadas por tos o estornudos. ${ }^{3}$ El objetivo de este estudio fue comparar el impacto de la dispersión del virus SARS-CoV-2 entre países con diferentes políticas de uso de mascarillas.

Objetivo: describir la evidencia disponible sobre la transmisión por COVID-19 e infecciones respiratorias agudas similares al COVID-19 y su prevención.

\section{MATERIAL Y MÉTODOS}

La revisión de la literatura se realizó siguiendo el protocolo de Cochrane para revisiones rápidas. La búsqueda incluyó artículos científicos en inglés que describieran o evaluaran la transmisión de la COVID-19 o infecciones respiratorias agudas como modo de transmisión, semejante en humanos o en espacios públicos abiertos. Se utilizaron los buscadores EMBASE y PubMed y se limitaron las fechas de búsqueda del primero de enero de 2019 al 31 de agosto de 2021. Además, se realizó una segunda revisión en medRxiv (https://www.medrxiv.org). Se requiere tomar una decisión basada en evidencia. La fecha de búsqueda fue del $1^{\circ}$ de enero de 2019 al 31 de agosto de 2021.

Todas las publicaciones y recomendaciones emanadas de éstas fueron valoradas en sucesivas reuniones respecto de su calidad y pertinencia. Estas recomendaciones son aplicables en cualquier tipo de fase epidemiológica, ya sea primaria o por rebrote infeccioso (o lo que se conoce como olas de contagio, aún en la fecha de elaboración de este artículo estaríamos en la tercera ola).

Con respecto a los cubrebocas o mascarillas que son adecuadas para la reducción de la transmisión de la COVID-19 podemos dividirlos en cinco grandes grupos: los cubrebocas o mascarillas de grado médico (también llamados quirúrgicos), los cubrebocas no médicos, los que contienen respiradores (como es el caso del N95, KN95, NK95), las caretas y los elaborados en casa con tela.

\section{RESULTADOS}

La eficiencia de los cubrebocas depende de la combinación de varios factores:
1. La capacidad del material con que son diseñados para bloquear la entrada y salida de partículas.

2. La cantidad de fuga que hay alrededor y el buen uso de quien lo porta.

El uso de una barrera física como el cubrebocas puede ser efectivo para evitar la diseminación de las gotas respiratorias. La filtración para controlar los aerosoles pasa por cinco mecanismos:

1. Sedimentación

2. Impacto por inercia

3. Intercepción

4. Difusión

5. Atracción electroestática

Para los aerosoles de uno a 10 micras los primeros dos mecanismos de filtración son los predominantes.

En una revisión rápida sobre medidas preventivasevidencia de transmisión, se comparó el uso de cubrebocas, la cual mostró que el riesgo de cualquier infección respiratoria, incluidas las de coronavirus, disminuía con el uso de cubrebocas. Algunos estudios evaluaron la diferencia entre el cubrebocas FFP2 y las quirúrgicas N95, y algunos otros evaluaron el efecto de usar o no cubrebocas. ${ }^{4}$

\section{Cubrebocas o mascarillas médicas o quirúrgicas}

Este tipo de mascarilla es desechable y su ajuste relativamente holgado. Tienen en su composición tres capas de polímeros, aunque existen diferentes modelos con características específicas. Si son usadas adecuadamente pueden ayudar a bloquear gotas respiratorias, salpicaduras o gotículas que contengan virus, impidiendo su contacto con mucosas. Es importante que una vez utilizado se deseche adecuadamente en la basura y se realice un lavado de manos después de manipularlos. ${ }^{4}$ Es la recomendada para su uso cotidiano en el hospital.

\section{Cubrebocas o mascarillas no médicas}

Existen mascarillas desechables de un solo uso que no están certificadas para su empleo en entornos clínicos, pero son adecuadas para el uso comunitario. Son apropiadas para situaciones en las que la mascarilla podría humedecerse o ensuciarse $y$, por lo tanto, requiera ser desechada. En el caso de las mascarillas de tela, se prefiere que sean de tejido cerrado como el algodón o las mezclas de algodón, que permitan la respiración, y se sugiere que sean telas con dos o tres capas (Figura 1). ${ }^{5}$ 


\section{Cubrebocas o mascarillas con respiradores}

Este dispositivo respiratorio, comúnmente llamado N95, está diseñado para colocarse en el rostro de manera ajustada y es capaz de filtrar el $95 \%$ de las partículas, incluyendo muchos de los aerosoles que contienen partículas virales pequeñas, inclusive menores que los coronavirus. Estas mascarillas o cubrebocas están reservadas para el personal sanitario, y no deben ser utilizadas fuera de los sitios o procedimientos en donde haya generación potencial de aerosoles, como es el caso de la intubación, extubación o aspiración de secreciones, entre otros. ${ }^{6}$

\section{Sin respiradores, tipo KN95 o de alta eficiencia}

Los cubrebocas o mascarillas KN95 son un insumo indispensable para la atención de los pacientes con COVID-19. Son recomendables, pero la dificultad a veces estriba en que tienen un costo mayor y su disponibilidad se ha visto comprometida durante la pandemia, por lo que no debemos utilizarlos en contextos en los cuales no proporcionan un valor agregado al resto de las mascarillas.

\section{Caretas}

Para una protección adecuada deben cubrir por debajo del mentón, las orejas y deben quedar pegadas a la frente. Sus ventajas son que pueden usarse en forma indefinida, se limpian fácilmente con agua y jabón o desinfectantes de uso común y evitan que el portador se toque la cara.

\section{Cubrebocas hechos en casa}

Estas mascarillas de ninguna manera se recomiendan para los trabajadores de la salud que se encuentran en contacto con pacientes COVID-19. Como se ha demostrado con la influenza, su uso por trabajadores de la salud lleva a mayor frecuencia de contagios que el uso de mascarillas quirúrgicas.

Portar un cubrebocas hecho en casa puede ayudar a impedir la diseminación de agentes infecciosos y en la situación de una pandemia donde la población general no tiene acceso a los KN-95 ni a las mascarillas quirúrgicas, el uso de cubrebocas hechos en casa puede ser una alternativa. Pero, para lograrlo, no deben existir fugas. ${ }^{\text {? }}$

La Secretaría de Salud no recomienda el uso de las caretas como reemplazo de los cubrebocas o mascarillas,

Figura 1:
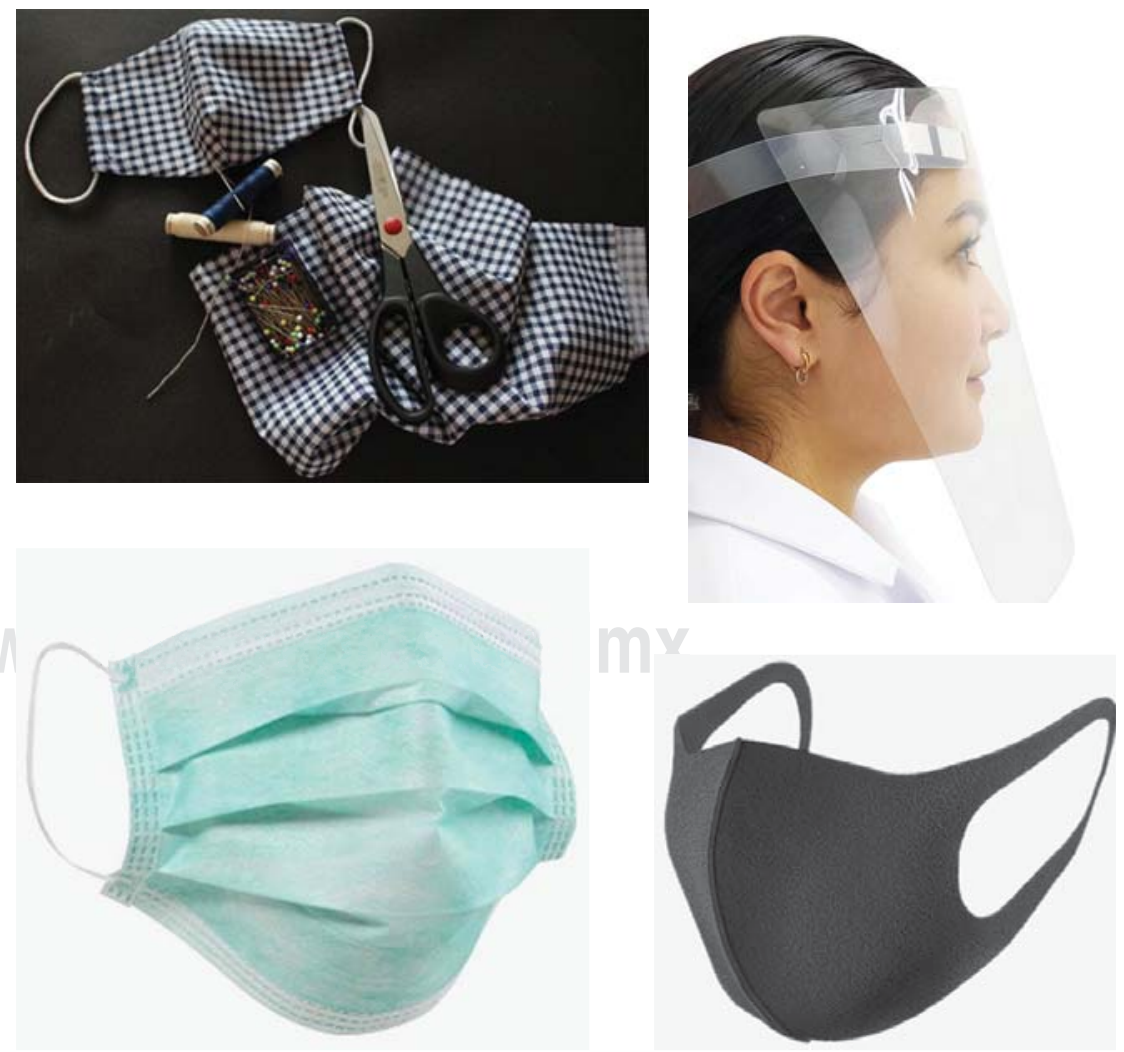

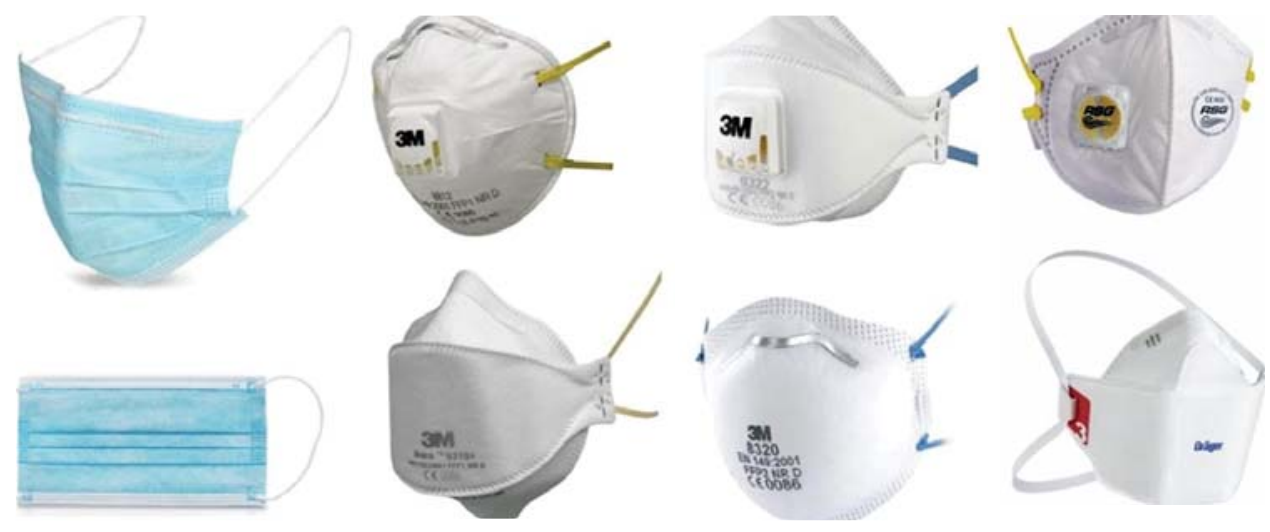

Figura 2:

Cubrebocas usados contra la pandemia de coronavirus, recomendados. sobre todo bajo la premisa de que estos instrumentos en sí mismos no cubren adecuadamente la nariz y la boca y, por lo tanto, permiten la emisión de partículas respiratorias.

Todos los resultados del metaanálisis en la población general indican que usar cualquier cubrebocas es mejor que no hacerlo. Los metaanálisis que estudiaron los cubrebocas FFP2, N95, NK95 y las quirúrgicas en trabajadores de la salud, concluyeron que no había diferencia entre estos.

\section{Boletín sobre COVID-19 (Figura 2)}

Los KN95, NK95 no deben lavarse, -y aunque los fabricantes suelen recomendar que sean insumos de un solo uso- durante la pandemia se han establecido protocolos para un uso de hasta 40 horas. ${ }^{8}$ Los N95 originalmente fueron creados para actividades industriales, y existe una variante de estos dispositivos que cuentan con una válvula de respiración o exhaladora. La Organización Mundial de la Salud (OMS) rechaza el uso de dispositivos con válvulas de exhalación como estrategia para reducir la transmisión del SARS-CoV-2. ${ }^{9}$

Hasta el momento actual (noviembre de 2021) en los metaanálisis evaluados específicos para la COVID-19, ${ }^{8}$ los autores han demostrado que el uso del cubrebocas o mascarilla reduce el riesgo de infección en los tres tipos de coronavirus, especialmente para prevenirla. Se concluye que los cubrebocas (quirúrgicos o de algodón con varias capas) reduce el riesgo de infección en la población, si se mantiene sana distancia de seguridad de 1.5 metros. El uso de caretas aumenta la protección. ${ }^{9}$

\section{Beneficios y riesgos de usar cubrebocas}

Los dos principales beneficios obtenidos por el uso de cubrebocas son: protección personal y para el resto de la comunidad. Impidiendo que el portador de la mascarilla transmita el virus al respirar, hablar, toser o estornudar. ${ }^{10}$ El cubrebocas también provee beneficios al portador, ya que reduce el inóculo en caso de exposición al virus. El cubrebocas o mascarilla filtran la mayoría de las partículas virales dependiendo del tipo, pero no todas, haciendo que el portador del cubrebocas libere una determinada dosis de carga viral. ${ }^{11}$ En algunas enfermedades infecciosas, una carga viral menor está relacionada con un transcurso menos grave de la enfermedad, como se ha demostrado con la COVID19. Si la mayoría de la población usara cubrebocas, estarían menos expuestos al contagio, además de una dosis reducida del virus SARS-CoV-2, minimizando el riesgo de desarrollar la COVID-19 más grave. Asimismo, promueve la inmunidad comunitaria, disminuyendo así la velocidad de propagación del virus. ${ }^{12}$

\section{Uso correcto e incorrecto del cubrebocas (Figura $3 A$ y B)}

Desde la Universidad Biomédica Rafael Guízar y Valencia, invitamos a la comunidad a redoblar los esfuerzos que colectivamente nos ayudarán a salir adelante y con salud sin contagio en estos tiempos difíciles de pandemia.

El uso de cubrebocas/mascarillas durante esta pandemia ha sido de tal impacto, que se ha logrado salvar miles de vidas, en conjunto con las otras medidas de prevención y la inmunización, que ha sido fundamental. La educación sobre el uso generalizado del cubrebocas permanente al salir a la calle, guardar la sana distancia (1.5 mts), lavarse las manos cuantas veces sea necesario, usar gel-alcohol $70 \%$ y sanitizar los espacios cuando esto sea posible, entre otras medidas marcan la diferencia en detener el contagio del coronavirus SARS-CoV-2 y sus variantes delta y ómicron. Las medidas de mitigación en todos los actores de la sociedad es sin lugar a dudas nuestra mejor herramienta. 


\section{CONCLUSIÓN}

La recomendación del uso generalizado de mascariIla es una medida con suficiente respaldo científico para reducir el número, velocidad de contagios y mortalidad por el virus SARS-CoV-2, en medidas de contención para episodios críticos similares al de la actual pandemia.

¿Nos encontramos ante el nacimiento de una era que transita hacia la paranoia en la sociabilidad pública? Durante el periodo de cuarentena nos dimos a la tarea de hacer recomendaciones avaladas por la ciencia; día con día la OMS cataloga como infodemia (fake news) artículos o comentarios de las redes sociales. Haciendo que el imaginario colectivo dejara de asistir a nuestras actividades cotidianas.

Esos riesgos moralmente inaceptables son los daños provocados al medio ambiente, a la salud o la vida de los humanos». Éste es el «principio de precaución», que debemos llevar a cabo si queremos que la población no pague con su vida, su salud y con todas las demás repercusiones, como las económicas.
A
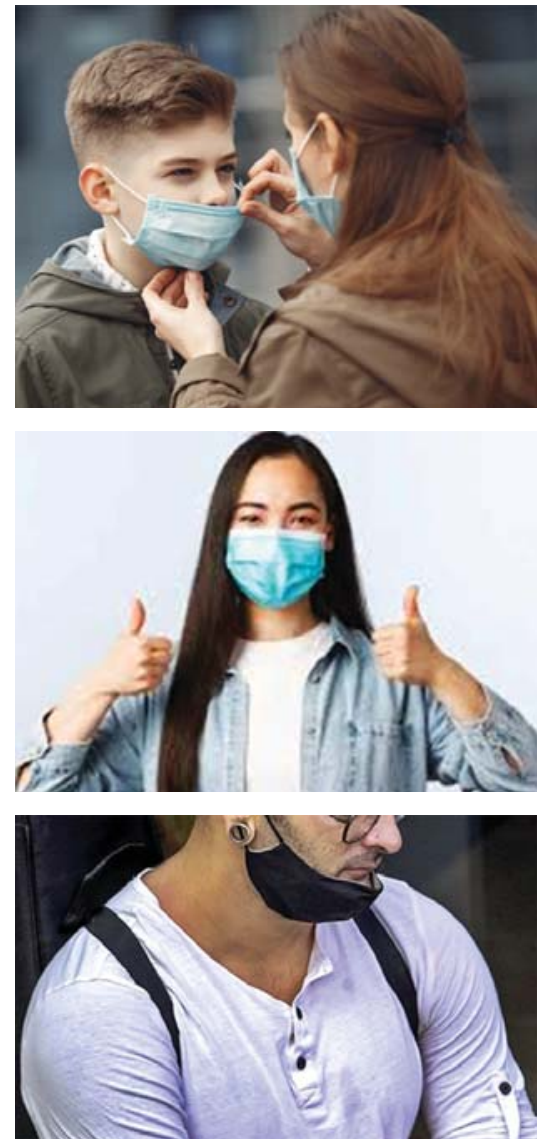

Figura 3:

A) Uso correcto e incorrecto de los cubrebocas. Siga las recomendaciones de la OMS. B) Los cubrebocas/mascarillas más recomendados protegen contra todas las variantes del coronavirus.
B
N95

COVID Ómicron

COVID Delta

COVID Alpha

Bacterias

KF94

COVID Delta

COVID Alpha

Bacterias
COVID Ómicron

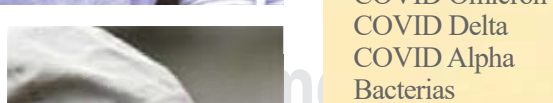

COVID Alph

\section{$\%$ de efectividad de cubrebocas}
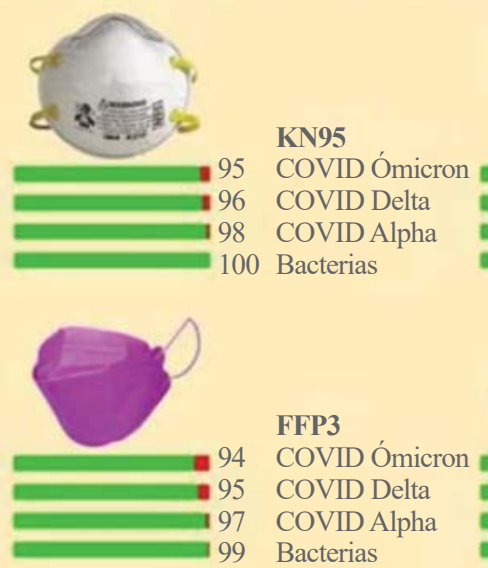

FFP3

COVID Ómicron $=86$

COVID Delta

COVID Alpha

Bacterias

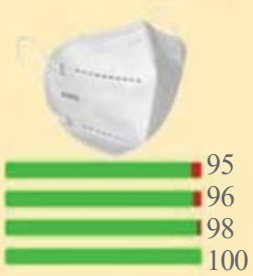

Quirúrgico (de 3 capas)

COVID Ómicron

COVID Delta

COVID Alpha

Bacterias

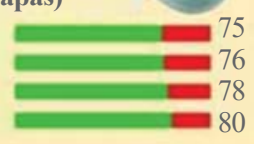

FFP2

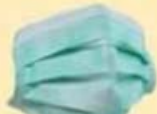

COVID Ómicron

COVID Delta

COVID Alpha

Bacterias

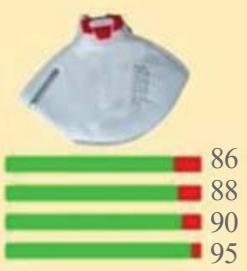

FFP1
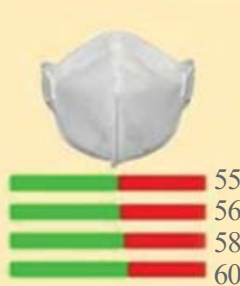

Quirúrgico (1 capa)

COVID Ómicron $=15$

COVID Delta

COVID Alpha

Bacterias
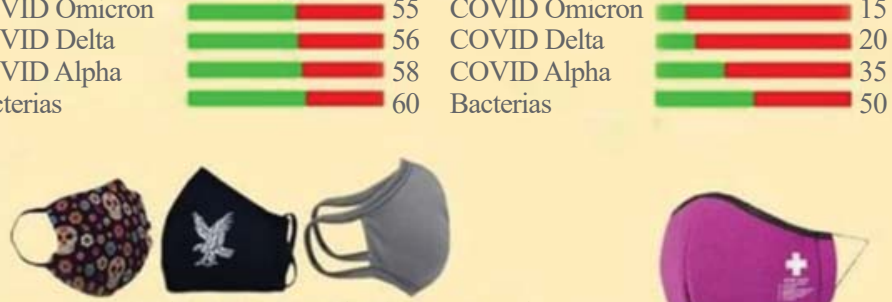

Tela (algodón, poliéster, lycra, nailon) COVID Ómicron

COVID Delta

COVID Alpha

Bacterias

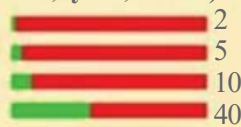

Esponja

COVID Ómicron

COVID Delta

COVID Alpha

Bacterias

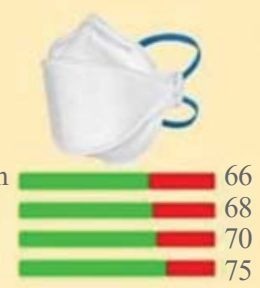

* Fuentes: UNAM-OMS-Washington University School of Medicine. 


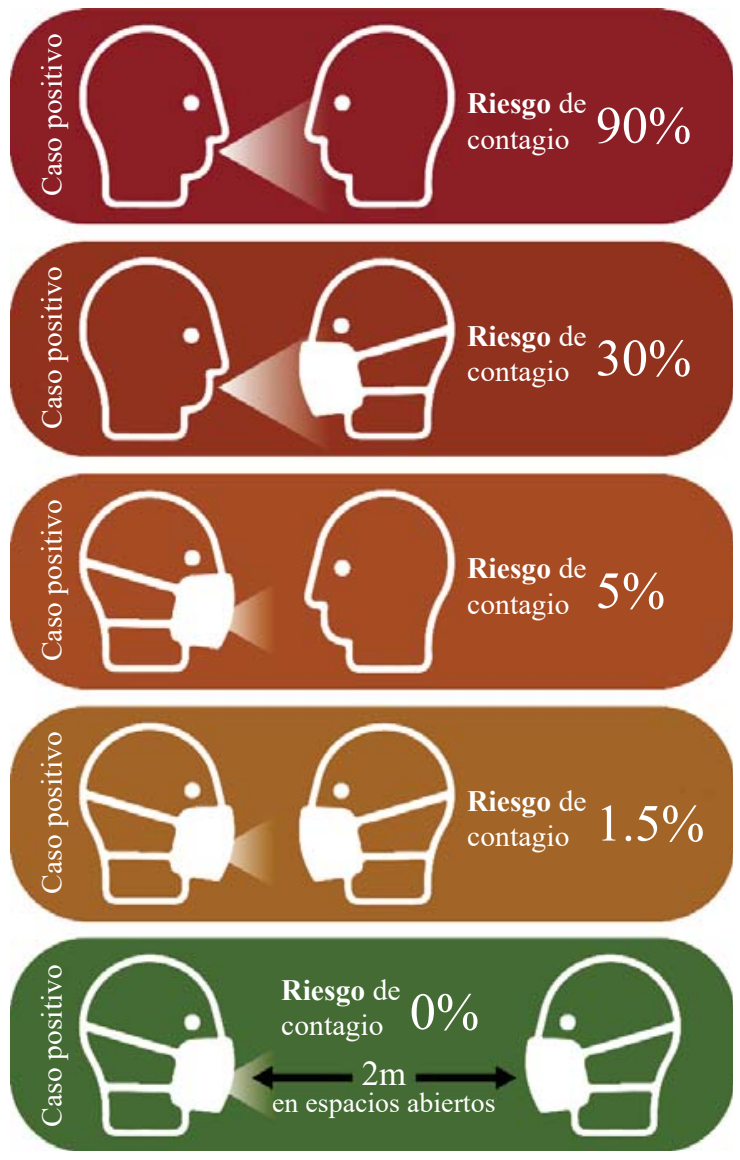

Figura 4: La sana distancia puede reducir el contagio hasta $0 \%$.

\section{¿Qué hacer para mantenerse y mantener a los demás a salvo de la COVID-19 OMS/2021?}

Guarde al menos 1.5 metros de distancia entre usted y otras personas, a fin de reducir su riesgo de infección cuando otros tosen, estornudan o hablan (Figura 4). Cuanto mayor distancia, mejor. Convierta el uso del cubrebocas o mascarilla en una parte normal de su interacción con otras personas.

Lávese las manos antes de ponerse la mascarilla, y también antes y después de quitársela y cada vez que la toque. Asegúrese de que le cubra la nariz, la boca y el mentón. Los cubrebocas deben ser manipulados sólo en las tiras o bandas para las orejas y sin tocar la superficie del mismo. Cuando se quite el cubrebocas o mascarilla, guárdela en una bolsa de plástico limpia; si es de tela lávela cada día y si es una mascarilla médica, tírela y destrúyala. No utilice mascarillas con válvulas.

Las reuniones al aire libre son más seguras que en interiores, en particular si los espacios son pequeños y carecen de circulación de aire exterior.
Los cubrebocas o mascarillas son un componente indispensable para la prevención de la COVID-19.

La higiene de manos frecuente, la sana distancia de al menos 1.5 metros, y evitar salir de casa si no es necesario, son acciones para la disminución de contagios por el SARS-CoV-2. El uso de los cubrebocas (mascarilla) protege no sólo a la persona que la usa, sino también a las demás personas. Usemos responsablemente las mascarillas por el bien de todos.

\section{REFERENCIAS}

1. Foucault, Michel. Microfísica del poder. Ediciones de la Piqueta: Madrid, 1980. Harvey, David. "La experiencia del espacio y el tiempo", en La condición de la posmodernidad. Investigación sobre los orígenes del cambio cultural, Amorrortu Editores: Buenos Aires, 1998.

2. Leal A. Peligro, proximidad y diferencia: negociar fronteras en el Centro Histórico de la Ciudad de México. En Alteridades, Universidad Autónoma Metropolitana-Unidad Iztapalapa, 2007;17(34):27-38.

3. Bourouiba L. Turbulent gas clouds and respiratory pathogen emissions potential implications for reducing transmission of COVID-19. JAMA. 2020;323:1837-1838. doi. 10.1001/ jama.2020.4756.

4. Medina C, Chavira J, Aburto T, Nieto C, Contreras-Manzano A, Segura $L$ et al. Revisión rápida: evidencia de transmisión por Covid-19 e infecciones respiratorias agudas similares en espacios públicos abiertos. Salud Pública Méx. 2021;63:232-241. Disponible en: https://doi.org/10.21149/11827

5. Hernández PF, Vargas PEI, Tello RMR. Creencias sobre la pandemia y las medidas de protección en pacientes que acuden al servicio de urgencias por probable COVID-19. Rev CONAMED. 2021;26(3):134-142.

6. Anderson EL, Turnham P, Griffin JR, Clarke CC. Consideration of the Aerosol Transmission for COVID-19 and Public Health. Risk Analysis. 2020;40(5):902-907. Available in: https://buff.ly/3aiote7

7. Ramírez-Guerrero JA. La importancia del cubrebocas en la población general durante la pandemia de COVID-19. Med Int Méx. 2021;37(1):94-109.

8. World Health Organization. Coronavirus disease (COVID19): masks [Internet]. WHO; 2020. Available in: https://buff. Iy/2L9xA8w.

9. Centers for Disease Control and Prevention. Considerations for Wearing Masks [Internet]. CDC; 2020. Available in: https://buff. Iy/2YPcPCO

10. Chu DK. Physical distancing, face masks, and eye protection to prevent person-to-person transmission of SARS-CoV-2 and COVID-19: a systematic review and meta-analysis. Lancet. 2020;395:1973-1987. Available in: https://buff.ly/3cpvtVm.

11. Mitze T, Kosfeld R, Rode J, Walde K. Face masks considerably reduce COVID-19 cases in Germany. Proc Natl Acad Sci USA. 2020; 202015954. Available in: https:// buff.ly/2YvRtK0.

12. US Food \& Drug Administration. N95 Respirators, Surgical Masks, and Face Masks. [Internet]. FDA; 2020 [cited 2020 Nov 19]. Available in: https://buff.ly/30c10u

Conflicto de intereses: Los autores declaramos no tener ningún conflicto de intereses, no recibimos aportaciones de organizaciones o empresas internas o externas.

Financiamiento: El financiamiento corrió a cargo de los investigadores. 